\title{
Kinematics of swimming of penguins at the Detroit Zoo
}

\author{
Brian D. Clatr and Willy Bemis* \\ Division of Biological Sciences, The University of Michigan, Ann Arbor, \\ Michigan, U.S.A.
}

\section{(Accepted 14 November 1978)}

(With 8 figures in the text)

\begin{abstract}
Kinematic parameters were examined in a study of the swimming abilities of seven species of penguins housed at the Detroit Zoo. Penguins produce thrust over both halves of the wing stroke cycle, as observed in fishes using the caudal or pectoral fins for locomotion, but not in other birds in level forward flight. Unpowered gliding phases between wing strokes were observed in all species at swimming speeds less than $1.25 \mathrm{~m} / \mathrm{sec}$, while Emperor, King and Adélie penguins interpose gliding phases over a broad range of speeds. Videotape records reveal that length-specific speed is correlated with increases in wingbeat frequency and, for most of the species examined, stride length. These findings are in contrast to those reported for other, flying birds, which maintain a relatively constant wingbeat frequency but vary stride length with forward speed, and for most fishes, which vary speed with tailbeat frequency but maintain a constant stride length. The results are somewhat comparable to those reported for Cymatogaster, a fish which uses the pectoral fins for locomotion. Drag coefficients of three gliding Emperor penguins were 2.1, 3.0 and $3 \cdot 0 \times 10^{-3}$ at Reynolds numbers of $1.25,1.62$ and $1.76 \times 10^{6}$, respectively.
\end{abstract}

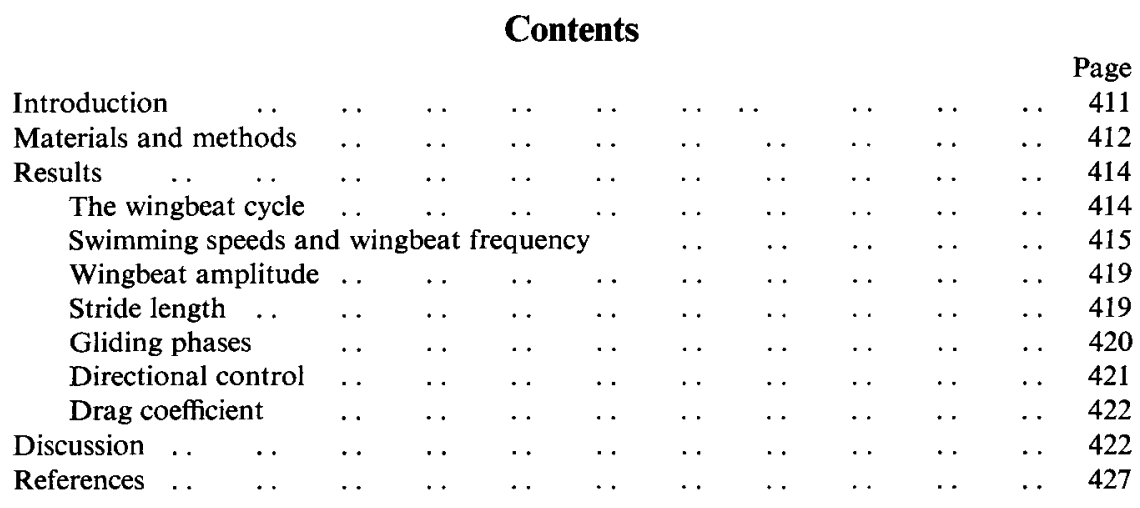

\section{Introduction}

Several lineages of birds have independently acquired aquatic habits. While some forms swim only on the water surface, many have evolved the capacity to swim underwater for moderate periods of time. Storer (1958) considers five extant groups to be the most specialized for submarine locomotion: loons (Gaviidae) and grebes (Podicipedidae), which swim by moving their feet, and auklets, murres, and puffins (Alcidae), diving petrels (Pelecanoididae) and penguins (Spheniscidae), which use their wings for propulsion.

*Present address: Department of Zoology, University of California, Berkeley, California, U.S.A. 
Other groups of birds have been reported to make limited use of wings as a supplement to propulsion by the feet (Owre, 1967; Brooks, 1945).

Penguins have lost the capacity for flight (although some authors hold that their ancestors never flew; see Simpson, 1946, for review) and show perhaps the most extensive series of morphological specializations for swimming of any of the aquatic birds. Penguins differ from flying birds in having the wings reduced in both length and area. The wings of penguins are shaped like hydrofoils, with contours largely determined by the skin; the same short, stiff feathers cover both the wings and body. The wing skeleton is dorsoventrally compressed, and the joints between its elements allow comparatively little movement (Shufeldt, 1901). The long bones of penguins (as well as of certain other diving birds) are not pneumatic and the air sacs are reduced. This probably reflects a tendency of these aquatic animals to conform to the density of the surrounding medium, thus reducing the force tending to displace them vertically (Meister, 1962). The intrinsic wing musculature is also reduced in penguins (Gervais \& Alix, 1877; Stegman, 1970). The supracoracoideus, the principal muscle of wing elevation in birds is very large in penguins, purportedly reflecting the increased effort required to elevate the wing underwater (Owen, 1866; Dabelow, 1925).

The submarine swimming movements of birds have been the subject of several studies. The feet provide the motive force in coots (Neu, 1931), grebes (Frank \& Neu, 1929; Dabelow, 1925), cormorants and loons (Dabelow, 1925). Locomotion by movement of the wings has been described in murres (Stettenheim, 1959; Spring, 1971), and in penguins (Dablow, 1925; Neu, 1931; Kooyman et al., 1971).

The wing stroke of penguins is known to resemble that of flying birds. In fact, many popular accounts of penguins describe their swimming movements as being identical to the flying movements of other birds (Romer, 1959; Terres, 1968; Simpson, 1976). Observations at the Berlin Zoological Garden, however, led Dabelow (1925) to the conclusion that penguins and other submarine birds must drive the upstroke of the wing with substantial muscular force to overcome the resistance of water; in contrast, the upstroke in flying birds is essentially passive, and occurs in part through the simultaneous descent of the body. Neu (1931) describes several other characteristics in which the wing stroke of penguins differs from that of flying birds. As his observations were of penguins swimming on the surface of a shallow tank, they may not be directly applicable to animals swimming freely underwater.

The present study describes the kinematics of the wing stroke of several species of penguins swimming underwater and compares them to the movements of the propulsive appendages in other swimming and flying vertebrates.

\section{Materials and methods}

Penguins were studied and filmed at the Detroit Zoo Penguinarium. The display includes a glass-walled triangular moat with sides $15 \mathrm{~m}$ in length along which the animals can swim continuously. The moat is about $2 \mathrm{~m}$ deep, varies in width from 1.5 to $2.0 \mathrm{~m}$, and contains about 160,000 litres of fresh water maintained at $12^{\circ} \mathrm{C}$ (Drake, 1969). A slow counter-clockwise current in the moat was estimated to vary between 3 and $8 \mathrm{~cm} / \mathrm{sec}$ by timing debris drifting in the water.

The penguinarium houses between 50 and 60 birds in the display area. Seven of the 18 extant species of penguins are currently represented at the penguinarium, including representatives of five of the six extant genera. Table I lists the species studied. 


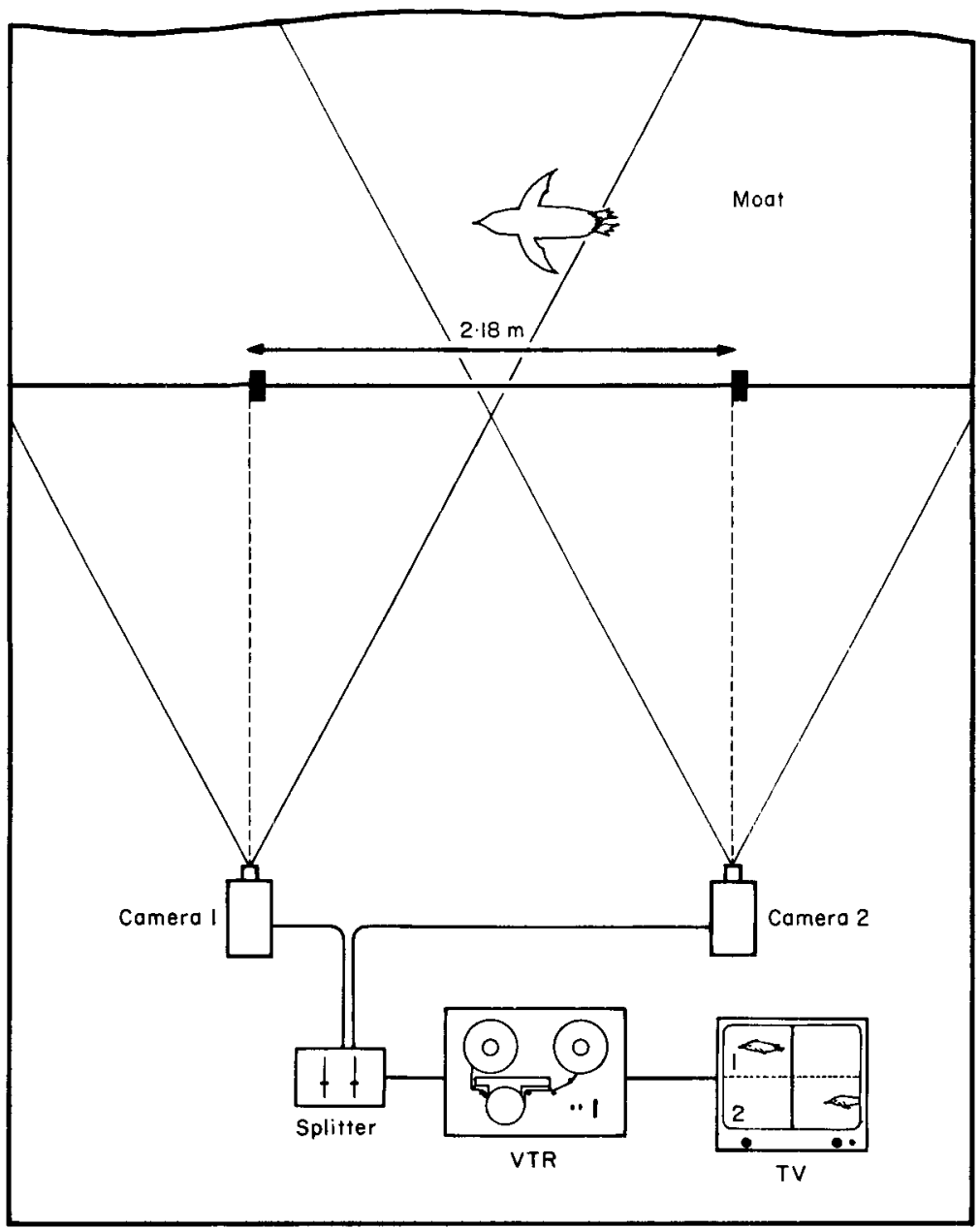

FIG. 1. Diagram of the arrangement of videotape equipment used to minimize the influence of parallax on speed measurements. Cameras are positioned perpendicular to the moat opposite supporting posts. With this arrangement, the distance of the penguin from the cameras does not affect the fields in which the image of the bird crosses those of the posts.

Four recording techniques were used:

(a) Penguins were timed with a stopwatch while they swam over distances of $8-11 \mathrm{~m}$; the number of wing strokes made over these distances was also recorded. Birds were only recorded when they swam away from the sides and surface of the moat and beat their wings continuously.

(b) Speed, length-specific speed and rate of wingbeat while the penguin traversed a $2.18 \mathrm{~m}$ course were calculated from a videotape made using the method illustrated in Fig. 1. Two Sony 3210 cameras were connected to a Sony Special Effects Generator 1 and a Sony 3650 videotape recorder (60 images/sec). Once turned on, the recorder was allowed to run continuously for the duration of the tape. The speed is taken as the course length times the framing rate divided by the number of frames the animal required to swim the length of the course. Length-specific speeds are obtained by dividing the framing rate by the number of frames the body takes to pass a line 
perpendicular to the axis of travel. For convenience of measurement, body length is taken as the distance from the base of the bill to the tip of the tail. Wingbeat frequency is calculated from the number of frames required for the wings to complete several, usually at least three, wingbeat cycles.

(c) Additional length-specific speeds and wingbeat rates are calculated from a videotape recorded with a single camera. In this case, the wingbeat frequency was determined only over a single cycle.

(d) Super 8 and $16 \mathrm{~mm}$ ciné-films were made using Kodak High Speed Ektachrome film exposed with either ciné lights or stroboscopic illumination. A super 8 ciné-film was taken with a Canon 814 Auto 8 camera at 24 frames/sec and analysed with a Kodak Ektagraphic MFS 8 analytical projector. A $16 \mathrm{~mm}$ film was made using a Beaulieu R76 camera modified to trigger two Strobex 100 power supplies with Strobex 74 lamps. A $2 \mathrm{~m}$ scale and a timing device were included in the field of the $16 \mathrm{~mm}$ film. Tracings of the $16 \mathrm{~mm}$ ciné-film were prepared using a Vanguard Motion Analyser M16 C with an S13 rear projection screen.

Analyses were made of film and videotape sequences in which the penguins were swimming horizontally at constant speed, beating their wings continuously and maintaining a distance of at least one wingspan away from other penguins, the water surface, the sides and the bottom of the moat. Blackfoot penguins, in addition to being the most numerous species in the exhibit, swam actively during the videotaping sessions. Consequently, most of the data obtained from the videotape records are of Blackfoot penguins. Data from the videotapes are especially limited for Macaroni and Rockhopper penguins. While there are only three Little blue penguins in the display, two of these swam almost continuously; several swimming sequences were obtained. Several sequences showing Emperor and Adélie penguins swimming with interrupted wing strokes were analysed separately.

\section{Results \\ The wingbeat cycle}

Figure 2 shows the paths of the bill and wing tip over two successive wingbeats of a Little blue penguin (Eudyptula minor). The stroking plane in this species is essentially perpendicular to the long axis of the body, and the up- and downstrokes are roughly equal in duration. Although the angle of attack of the wing could not be determined, the regular vertical oscillations of the body with each wing stroke suggest that the wings transmit roughly equal forces with alternately positive and negative vertical components to the body on the up- and downstrokes, respectively. These observations suggest that the penguin wing acts as a hydrofoil held at a positive angle of attack on the downstroke and at an equivalent negative angle on the upstroke. The lift that is presumably generated over the wingbeat cycle is directed upward and forward on the downstroke and downward and forward on the upstroke.

Other species follow this pattern with few deviations. In larger species, especially in Emperor and King penguins, the wings bend to a marked degree during the beat cycle. During the upstroke of Emperor penguins in particular (Fig. 3) the wing shows a pronounced downward curvature from base to tip. Whenever wing curvature is observed, it is consistent with the notion that the wings experience an upward bending moment on the downstroke and a downward moment on the upstroke. In addition, King penguins frequently propel themselves with rapid, small amplitude oscillations of the base of the wing which cause the wing curvature to fluctuate almost continuously. 


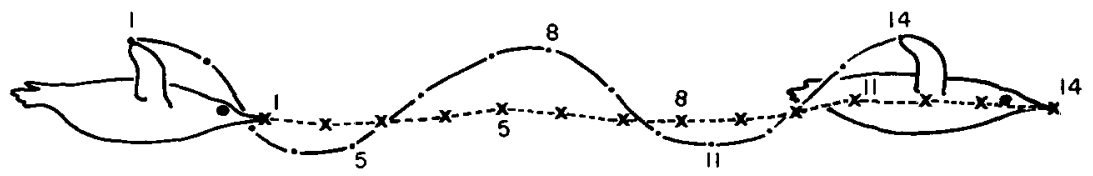

(a)
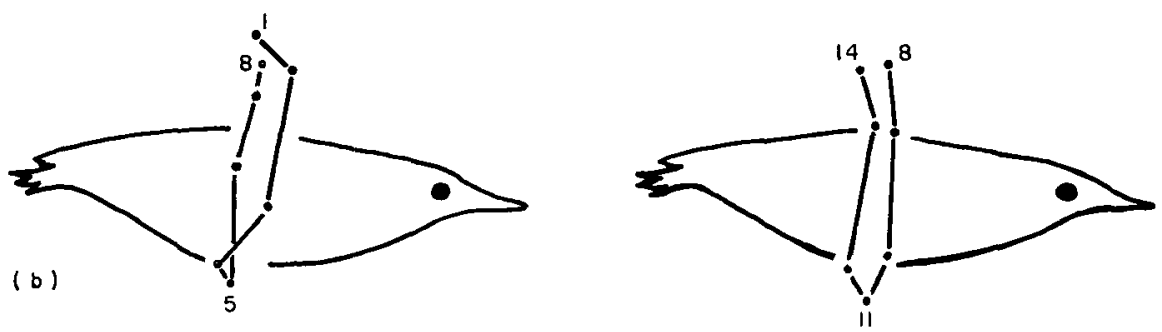

$0.042 \mathrm{sec}$ intervals

FIG. 2. Wingbeat cycle of a Little blue penguin (Eudyptula m. minor) traced from the $16 \mathrm{~mm}$ ciné-film. In (a), the path of the wing tip is shown by a solid line, and that of the bill by a dashed line. Frame numbers are given next to corresponding positions of the wing tip (points) and bill (crosses). The vertical movements of the wing tip and bill are roughly $180^{\circ}$ out of phase; as the wing descends (frames 1-5 and 8-11) the bill rises, and vice versa. (b) shows the path of the wing tip with respect to the body.

\section{Swimming speeds and wingbeat frequency}

Table I shows the maximum speeds and wingbeat frequencies observed for all species. Data included in this Table were taken by stopwatch and from videotape records. The ranges of swimming speeds of different species generally overlap each other, except those of Adélie and Rockhopper penguins, for which the sample sizes are small. The maximum speeds for Blackfoot penguins (Spheniscus demersus) were recorded immediately prior to leaps from the water surface.

Penguins usually beat their wings continuously when swimming horizontally at constant speed. However, in many sequences, including most in which the swimming speed is less than $1.25 \mathrm{~m} / \mathrm{sec}$, all species interpose phases of unpowered gliding of varying duration between single beats or groups of beats. Such sequences were omitted from the analyses of speed as a function of wingbeat frequency and of stride length. In addition, King, Emperor and Adélie penguins typically interpose glides between wing strokes over a much wider range of speeds than do the other species. Consequently, most data from the latter two species have been analysed separately (see p. 420), while data on King penguins are omitted due to inadequate sample size.

Figure 4 shows speed as a function of wingbeat frequency for four species of penguins. In fish, when speed is expressed in body lengths travelled per unit time, there is a single linear relationship between finbeat frequency and speed which applies to all sizes and species examined which use caudal fin propulsion (Bainbridge, 1958; Hunter \& Zweifel, 1971). To test whether penguins of all sizes and species also conform to a single relationship between wingbeat frequency and speed, the data from Fig. 4 have been corrected for body length (Fig. 5). Figure 5 includes data from the videotape made with a single camera, for 

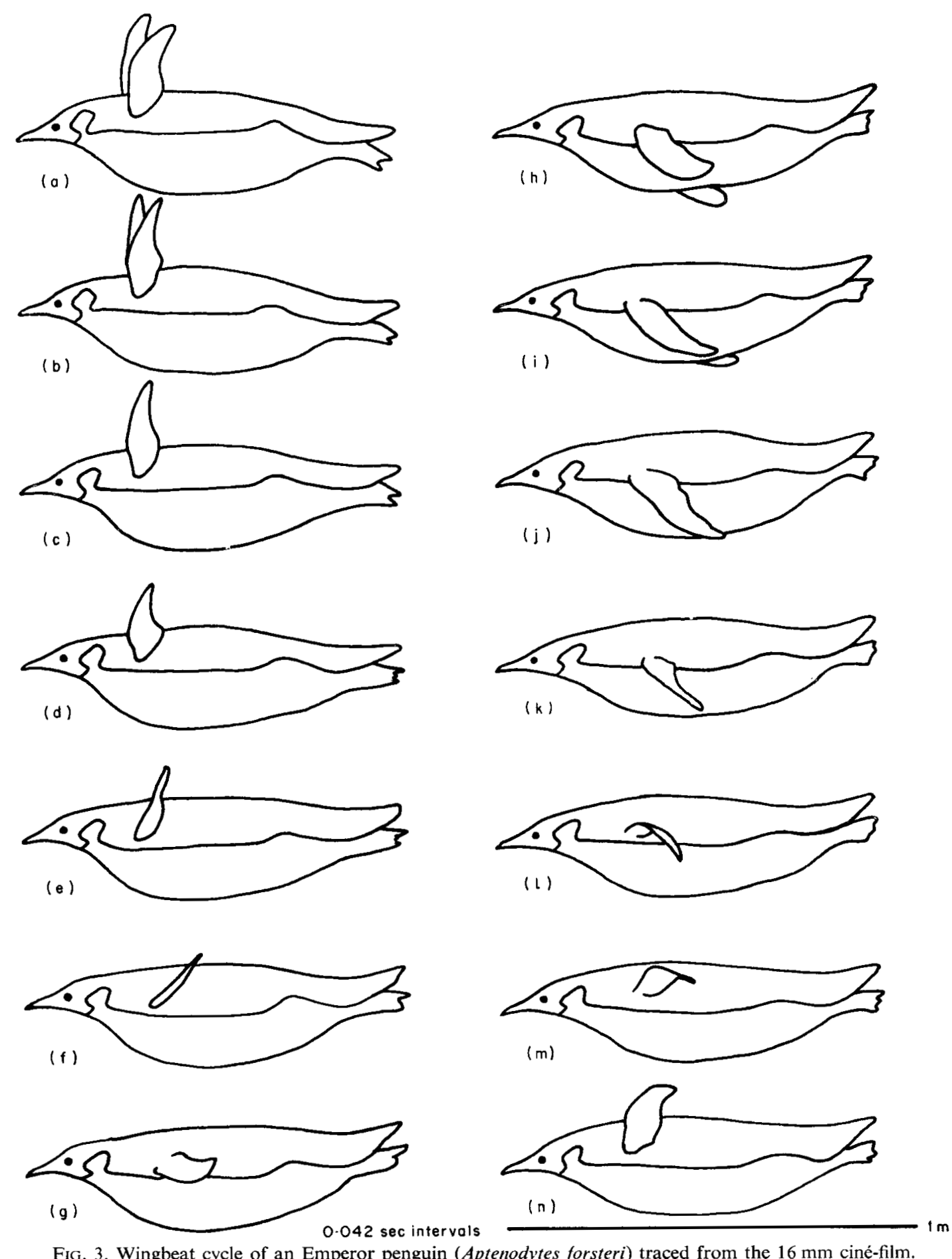

FIG. 3. Wingbeat cycle of an Emperor penguin (Aptenodytes forsteri) traced from the $16 \mathrm{~mm}$ ciné-film. 
T A B LE I

Species studied and swimming parameters

\begin{tabular}{|c|c|c|c|}
\hline Species & $\begin{array}{l}\text { Number of } \\
\text { animals in } \\
\text { exhibit }\end{array}$ & $\begin{array}{c}\text { Maximum } \\
\text { speed } \\
(\mathrm{m} / \mathrm{sec})\end{array}$ & $\begin{array}{l}\text { Maximum } \\
\text { wingbeat } \\
\text { frequency } \\
\text { (beats/sec) }\end{array}$ \\
\hline Aptenodytes forsteri, & & & \\
\hline Emperor penguin & 5 & $2 \cdot 26^{*}$ & $1 \cdot 50$ \\
\hline $\begin{array}{l}\text { Aptenodytes patagonica, } \\
\text { King penguin }\end{array}$ & 11 & $3 \cdot 35^{*}$ & $2 \cdot 85^{*}$ \\
\hline $\begin{array}{l}\text { Spheniscus demersus, } \\
\text { Blackfoot penguin }\end{array}$ & 17 & $3 \cdot 23 *$ & $3 \cdot 24^{*}$ \\
\hline $\begin{array}{l}\text { Eudyptes chrysolophus, } \\
\text { Macaroni penguin }\end{array}$ & 4 & $2 \cdot 29 *$ & $2 \cdot 62 *$ \\
\hline $\begin{array}{l}\text { Pygoscelis adeliae, } \\
\text { Adélie penguin }\end{array}$ & 10 & $1.98^{*}$ & $2 \cdot 50^{*}$ \\
\hline $\begin{array}{l}\text { Eudyptes crestatus, } \\
\text { Rockhopper penguin }\end{array}$ & 7 & $2 \cdot 18$ & $3 \cdot 13^{*}$ \\
\hline $\begin{array}{l}\text { Eudyptula } m . \text { minor } \\
\text { Little blue penguin }\end{array}$ & 3 & $1 \cdot 72$ & $3 \cdot 91$ \\
\hline
\end{tabular}

* Stopwatch values.

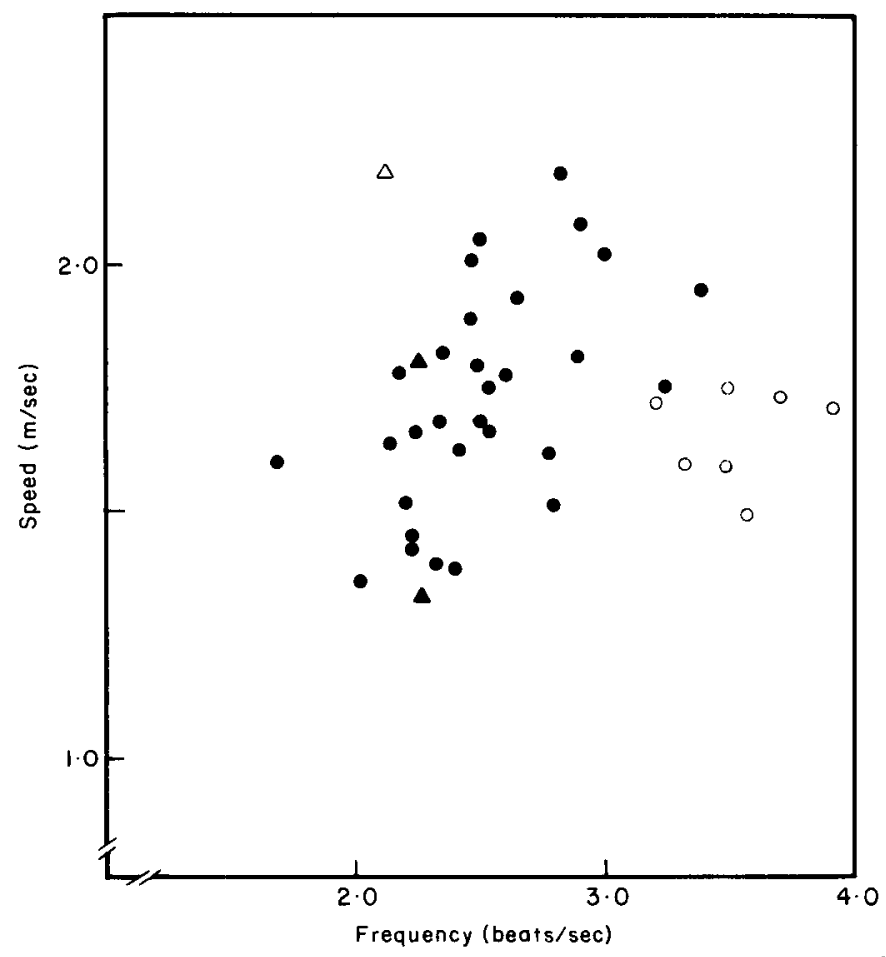

FIG. 4. Speed as a function of wingbeat frequency for four species of penguins. (O) Eudyptula m. minor; Spheniscus demersus; $(\triangle)$ Eudyptes crestatus; (A) Eudyptes chrysolophus. Data were taken from the videotape made using the technique illustrated in Fig. 1. 
which the only measure of speed was in body lengths per second. Because all of the species studied swim in the same range of speeds, small animals have high length-specific speeds, while large animals have low ones. Figure 5 suggests that all penguins may follow a single linear relationship between wingbeat frequency and length-specific speed, although the scatter is too large and the data too few in number to discount species-specific differences.

Some of the scatter in Fig. 5 may result from plotting values for different individuals of the same species. To determine whether the relationship between speed and wingbeat frequency holds for individual animals, single Rockhopper and Blackfoot penguins were observed for several sequences. As the resolution of videotape is limited, and individuals of a species difficult to identify while they are swimming, observations were made directly,

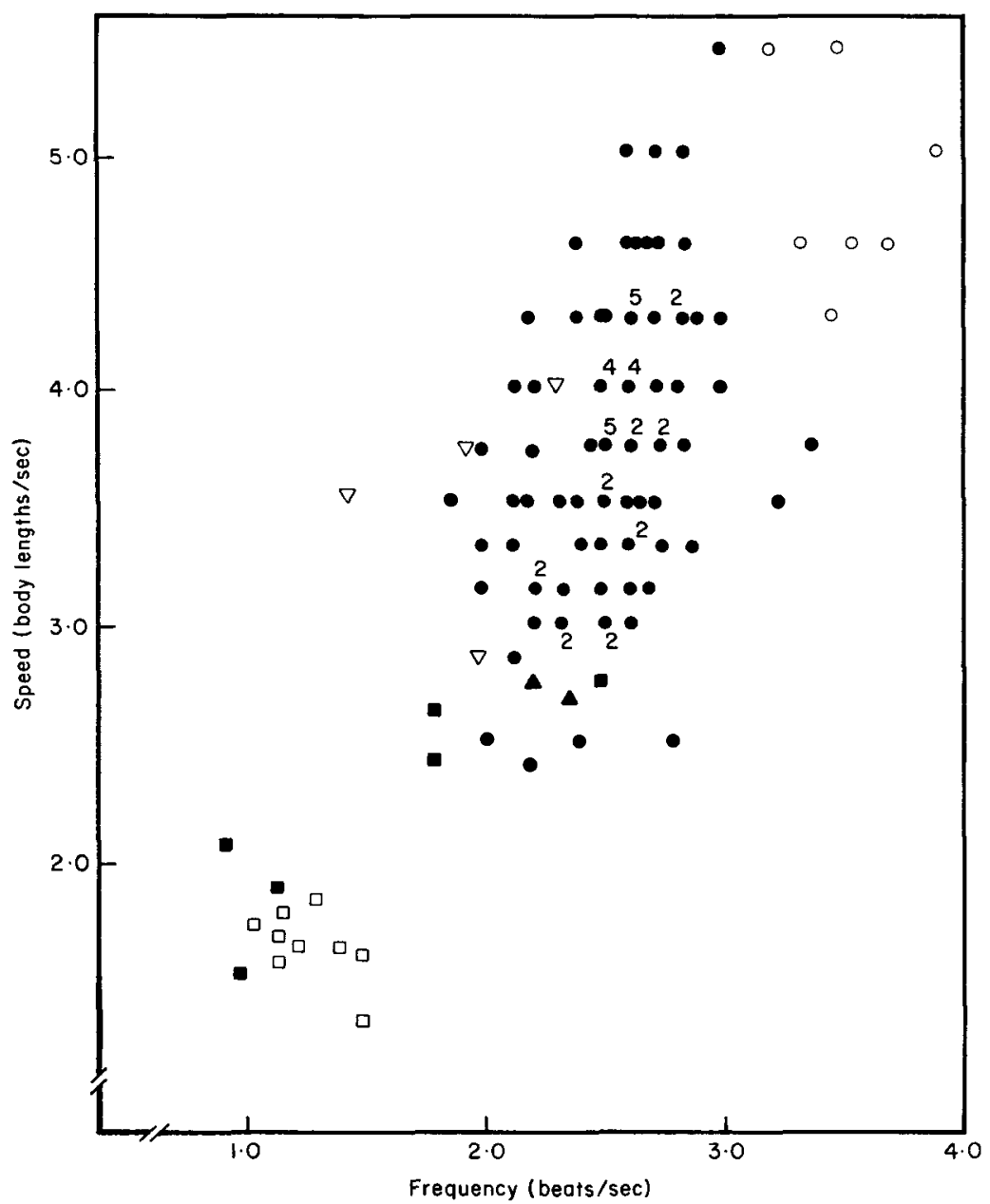

FIG. 5. Length-specific speed as a function of wingbeat frequency for six species of penguins. ( $\square$ ) Aptenodytes forsteri; (匹) Aptenodytes patagonica; ( $\bigcirc)$ Eudyptula m. minor; (๑) Spheniscus demersus; ( $\nabla$ ) Pygoscelis adeliae; (A) Eudyptes chrysolophus. Numbers next to points indicate coincident values. Data from two videotapes are combined. 
using a stopwatch and counting the wingbeats over a fixed course. These results, shown in Fig. 6, demonstrate that speed does vary with wingbeat frequency in individual penguins. However, the scattering of values is real, and may reflect undetected variations in parameters such as wingbeat amplitude, angle of attack and angle of sweepback.

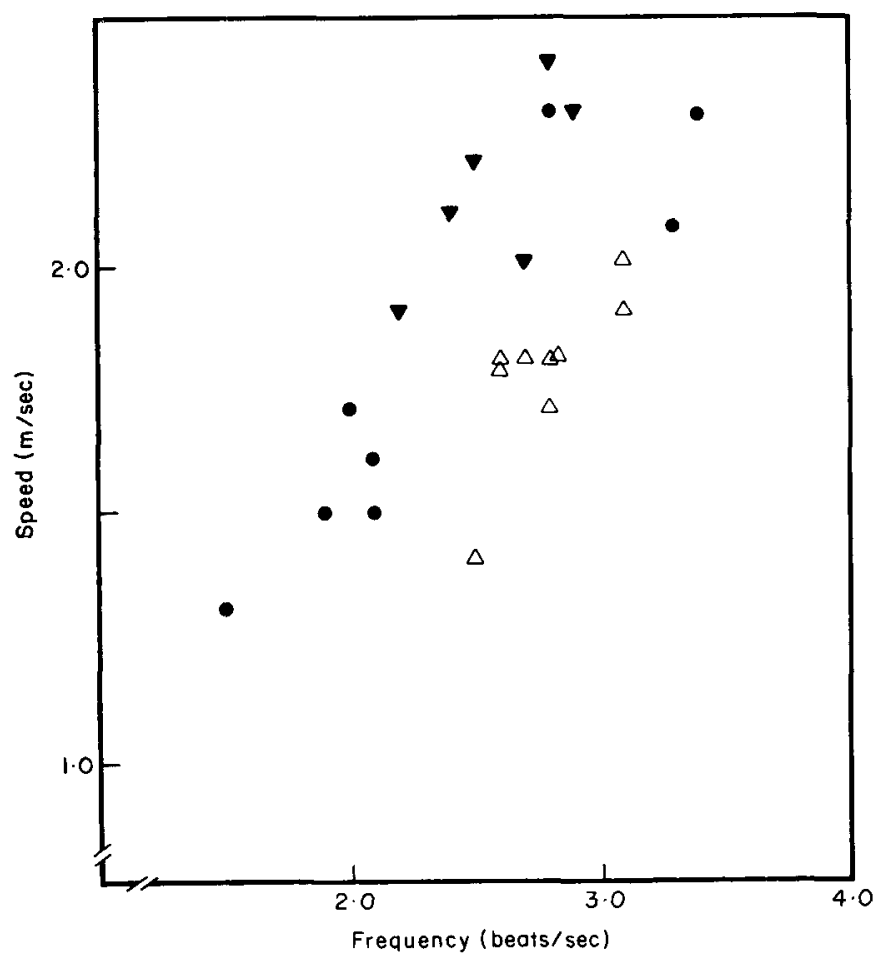

FIG. 6. Speed as a function of wingbeat frequency for three individual penguins. ( $)$ and ( $\mathbf{\nabla})$ Blackfoot penguins; $(\Delta)$ Rockhopper penguin. Animals were timed with a stopwatch.

\section{Wingbeat amplitude}

Due to the limited resolution of the recording devices used, it was not possible to make reliable estimates of wingbeat amplitude. Amplitude is low at low speeds and higher at high speeds, but it is unclear whether it increases continuously over the range of swimming speeds or increases sharply over a small range of slower speeds and remains at a maximum over the rest of the range. It is probable that amplitude does not remain at a low, constant value over the bulk of the range and increase only at the highest speeds.

\section{Stride length}

The term "stride length" as suggested by Wardle (1975) is here used to denote the distance travelled per wingbeat, in order to distinguish it from "wavelength", which is commonly applied to the distance between corresponding points on the waves travelling down the bodies of swimming fish. Figure 7 is a plot of speed in body lengths/sec versus stride length in body lengths. 
Visual inspection of Fig. 7 shows that this relationship appears to be distinct for each species or perhaps for each size of penguin. In the smaller species (Blackfoot, Adélie, Macaroni and Little blue penguins), speed increases with stride length. In Emperor and King penguins, speed is relatively constant over a wide range of stride lengths.

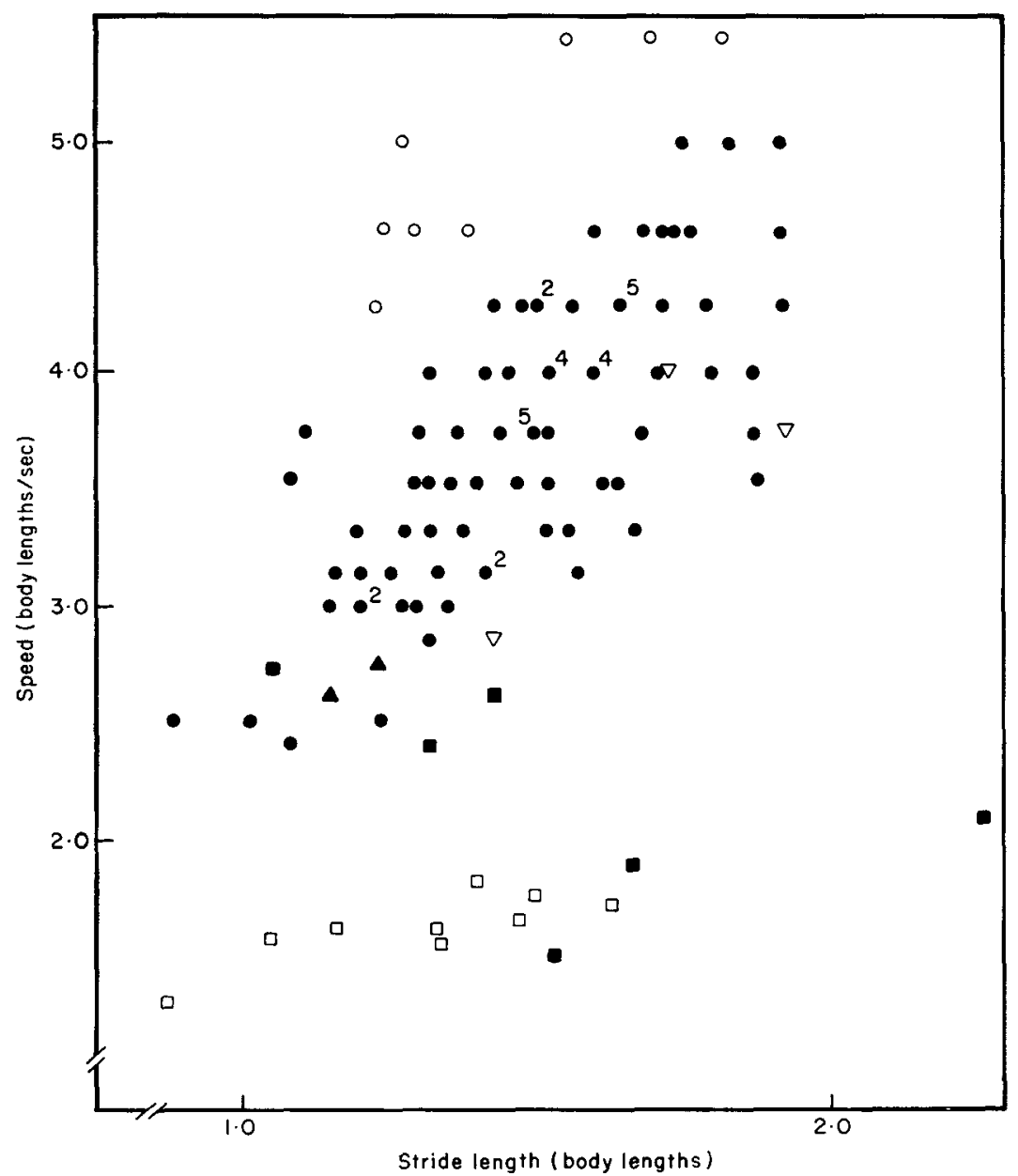

FIG. 7. Length-specific speed as a function of stride length for six species of penguins. Symbols are the same as in Fig. 5. Data from two videotapes are combined.

\section{Gliding phases}

Wingbeat frequency can be altered in two different ways: either the duration of the stroke is varied, or it is held constant while gliding phases are interposed between successive strokes. At speeds below $1.25 \mathrm{~m} / \mathrm{sec}$ all species separate successive wingbeats with gliding phases; however, Emperor, King and Adélie penguins typically interpose them at all speeds. In these species the gliding phases usually follow a partial upstroke, and the wings are either held in the stroking plane or swept back slightly behind it. At the end of the 
gliding phase the animal either makes another single stroke or resumes stroking continuously. Data collected on penguins showing gliding phases indicate that a wide range of speeds is achieved with minor variations in frequency (Fig. 8). Measurements of wing stroke duration in ten videotape sequences of Adélie penguins show that prior to a gliding phase the duration of the downstroke is less than it is during continuous stroking at comparable speeds $(0.35 \mathrm{sec}$ versus a mean of $0.54 \mathrm{sec})$. A single Emperor penguin timed with a stopwatch on seven sequences of three to four wingbeats each demonstrated a constant duration of wing stroke $(0.4-0.5 \mathrm{sec})$, with glides of varying durations between strokes.

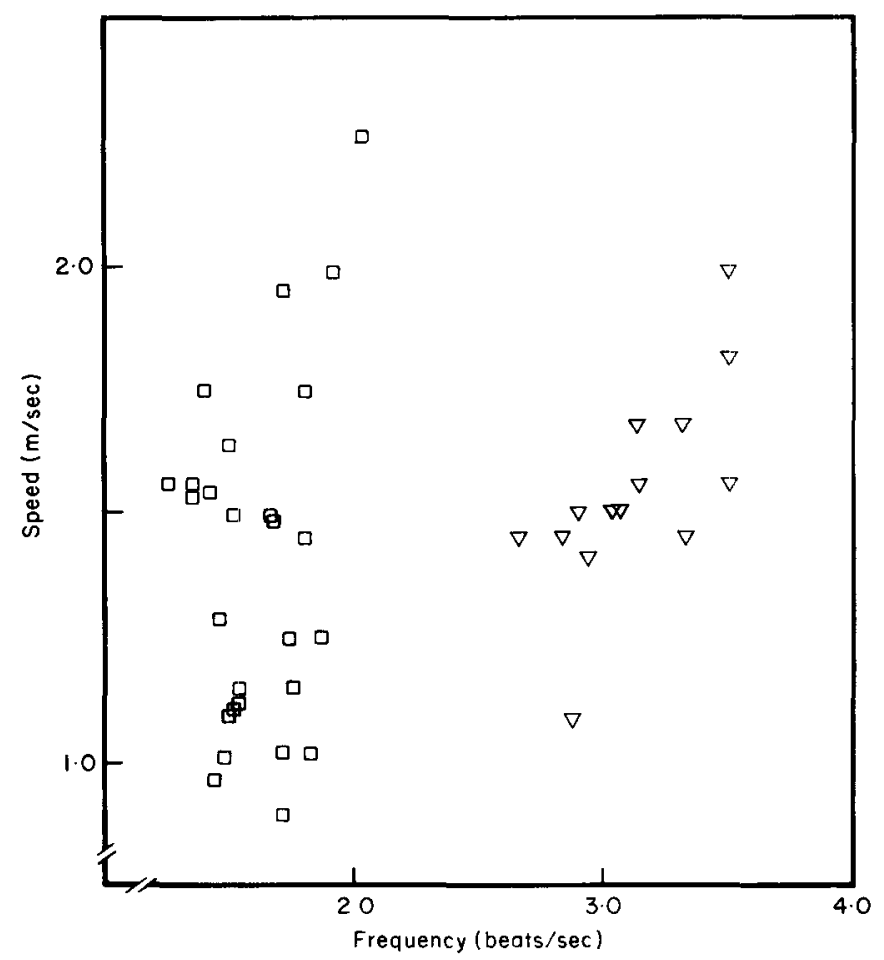

FIG. 8. Speed as a function of wingbeat frequency for Adélie ( $\nabla$ ) and Emperor $(\square)$ penguins. Animals were timed with a stopwatch.

\section{Directional control}

Penguins use the tail, feet and wings to control direction. The webbed feet and mobile tails are used to modulate pitch and yaw. The wings are used to change direction both during powered and unpowered swimming. King penguins seem particularly capable of executing complex underwater movements, and they also show more spinal flexion and extension than other species. When cornering, penguins roll so that the ventral side is to the inside of the turn, in contrast to flying aircraft and birds, which roll the ventral surface to the outside. 


\section{Drag coefficient}

Emperor penguins glided across the monitored $2.18 \mathrm{~m}$ distance apparently without making further movements in three videotape sequences. From these records, it was possible to estimate their drag coefficients. The percent change in length-specific speed over $2.18 \mathrm{~m}$ was converted to a deceleration by multiplying it by the mean speed and dividing it by the time the penguin took to cross the field. This deceleration was then multiplied by the mass of the animal (estimated at $30 \mathrm{~kg}$ from Stonehouse, 1967) to obtain the force acting on the animal during that interval. This force is assumed to be exclusively friction drag $(D)$, in which case it takes the form $D=0.5 p V^{2} A C_{d}$, where $p$ is the water density $\left(1.0 \mathrm{~g} / \mathrm{cm}^{3}\right), V$ is the speed in $\mathrm{cm} / \mathrm{sec}, A$ the wetted area of the animal in $\mathrm{cm}^{2}$, and $C_{d}$ the drag coefficient. The wetted area was estimated to be $6800 \mathrm{~cm}^{2}$, based on the sum of the wing area from Stonehouse (1967) and body surface area from Le Maho (1977). The drag coefficients found by substitution were $2 \cdot 1,3 \cdot 0$ and $3 \cdot 0 \div 10^{-3}$ at Reynolds numbers (based on body length) of $1.25,1.62$ and $1.76 \times 10^{6}$ respectively. Values used in these calculations are given in Table II.

TABLE II

Values used in the calculation of drag coefficient $C_{d}$

\begin{tabular}{ccc}
\hline $\begin{array}{c}\text { Penguin length } \\
(\mathrm{m})\end{array}$ & $\begin{array}{c}\text { Penguin speed } \\
(\mathrm{m} / \mathrm{sec})\end{array}$ & $\begin{array}{c}\text { Percent } \\
\text { deceleration }\end{array}$ \\
\hline 0.95 & 1.63 & $5 \cdot 6$ \\
1.00 & $2 \cdot 01$ & $7 \cdot 4$ \\
1.00 & $2 \cdot 18$ & 7.4 \\
\hline
\end{tabular}

Penguin mass was assumed to be $30 \mathrm{~kg}$ (Stonehouse, 1967).

Surface area was assumed to be $6800 \mathrm{~cm}^{2}$ (Stonehouse, 1967; Le Maho, 1977).

Water density was assumed to be $1.00 \mathrm{~g} / \mathrm{cm}^{3}$.

The kinematic viscosity of water at $12^{\circ} \mathrm{C}$ is 1.24 centistokes.

\section{Discussion}

The present observations on wing stroke, wingbeat frequency and stride length of penguins provide an interesting contrast to the kinematics of swimming and flying of other vertebrates. In most penguins, both frequency and stride length are modulated with speed, although these trends are less pronounced and may be absent in animals utilizing gliding phases. Both the up- and downstrokes occur in a plane perpendicular to the long axis of the body, and they appear to be equivalent to each other but opposite in direction and angle of attack. Thrust is apparently derived over both halves of the stroke cycle (a contention supported by the subequal sizes of the supracoracoideus and pectoralis major (Owen, 1866; Dabelow, 1925), the muscles chiefly responsible for wing elevation and depression) from the wings which act as hydrofoils.

Few reports in the literature address the kinematics of locomotion in penguins. Kooyman et al. (1971) give data suggesting that wingbeat frequency and stride length show little or no correlation with speed in diving Emperor penguins. However, since the authors included sequences in which penguins accelerated, the high variability they report does not seem unreasonable. The fastest speed observed by Kooyman et al. was $2.67 \mathrm{~m} / \mathrm{sec}$ for a 
specimen swimming between two holes in the Antarctic ice. This figure is close to the top speed of Emperor penguins recorded in the present study $(2 \cdot 26 \mathrm{~m} / \mathrm{sec})$, suggesting that the confines of the Detroit penguinarium do not severely limit the cruising ability of its occupants. It should be remembered that in neither the present study nor in that of Kooyman et al. were the animals compelled to swim at their maximum capacity.

The range of wingbeat frequency observed by Kooyman et al. was 0.4 to $0.8 \mathrm{beats} / \mathrm{sec}$, while the range for Emperor penguins in the present study is approximately 1-2 beats/sec. The ranges are roughly equivalent when allowance is made for gliding phases, which Kooyman et al. included in their measurements.

The kinematic characteristics reported by Neu (1931) conflict sharply with those of the present study. Neu describes a marked antero-posterior component of wing movement and a negligible angle of attack of the wing on the upstroke when captive penguins swim at or just beneath the water surface in a shallow $(0.8 \mathrm{~m})$ tank. Such behavioral differences were also noted in the present study and probably reflect responses to the hydrodynamic constraints imposed on a body moving at the air/water interface. Neu assumed that his observations apply to penguins swimming well beneath the surface. The present results show this to be untrue.

The literature on bird and bat flight disagrees regarding the relationship between wingbeat frequency and velocity. Birds vary wingbeat rate and pattern between take-off, hovering and forward flight (Brown, 1948). As penguins, being more or less neutrally buoyant, need not perform functions analogous to take-off or hovering, the discussion of wingbeat rates and their relationship to speed must be limited to animals in relatively rapid, forward flight.

Most reports suggest that wingbeat frequency in birds and bats is constant, although relatively few authors have considered whether it varies over a broad range of speeds. Greenewalt (1960a) and Hagiwara et al. (1968) report nearly constant wingbeat frequencies in hummingbirds whether they were hovering or flying rapidly. Constant wingbeat frequencies over a range of forward speeds have also been reported for laughing gulls (Tucker, 1972), budgerigars (Tucker, 1966; Aulie, 1970), finches (Aulie, 1971; Hagiwara et al., 1968), pigeons (Aulie, 1972), fish crows (Bernstein et al., 1973) and bats (Schnitzler, 1971; Thomas \& Suthers, 1973).

On the other hand, some authors report moderate modulation of frequency with speed. Norberg (1976) found that the wingbeat frequency decreased from about 13 to 10 beats/sec with an increase in speed from 2 to $3 \mathrm{~m} / \mathrm{sec}$ in long eared bats. Pennycuick (1968) shows a decrease in frequency of approximately $20 \%$ over the range of speeds from 7 to $18 \mathrm{~m} / \mathrm{sec}$ in the pigeon. While McGahan (1973) reports a wide range of wingbeat rates in vultures and condors, his were separate observations on single birds, each of which may have had its own intrinsic wingbeat rate.

Changes in speed of birds and bats flying in air may also be accompanied by changes in stride length, amplitude and angle of attack of the wing. If the frequency of wingbeats is constant or varies only slightly over a range of velocities, then the stride length must change; an increase of speed will then be accompanied linearly by an increase of stride length. Changes in wingbeat amplitude have been considered by only a few authors; in pigeons, amplitude first decreases, and then increases with speed (Pennycuick, 1968), while in hummingbirds it increases with speed (Hagiwara et al., 1968). In rapidly flying birds the angle of attack of the wing varies with time so that lift is generated throughout 
the wingbeat cycle, while thrust (the forward component of applied force) is applied only during the downstroke (see Brown, 1963, for discussion).

The kinematics of swimming of fish using caudal fin propulsion are known for a few cases. In goldfish, dace and trout the frequency of the tailbeat increases linearly with speed, while stride length is a constant fraction of body length (although these relationships do not hold at frequencies below 5 beats/sec). A single function describes the relationship between tailbeat frequency and speed expressed in body lengths/sec for all three species regardless of body size (Bainbridge, 1958). The amplitude of tailbeats increases with speed in dace and goldfish (Bainbridge, 1958) and trout (Bainbridge, 1958; Webb, 1971; Hudson, 1973) to a maximum that is a constant proportion of the body length. This maximum is usually reached at frequencies of about 5 beats/sec. In the trout the product of frequency and specific amplitude is linearly related to speed at all speeds (Webb, 1971). Tailbeat frequency increases with speed in Jack mackerel (Trachurus symmetricus) while tailbeat amplitude is constant at all speeds. Although stride length has not been specifically discussed, the slopes of speed versus frequency suggest that it is nearly constant (Hunter \& Zweifel, 1971).

Locomotion of the Surf perch (Cymatogaster aggregata) provides an interesting contrast with that of penguins as both derive thrust from bilaterally symmetrical movements of the pectoral appendages and both hold the body rigid. Except at low speeds ( $<1$ body length/ sec) when finbeat frequency is constant, frequency increases more or less linearly with speed in Cymatogaster. Although stride length has not been discussed, the slope of frequency versus speed and the decrease in relative duration of the gliding phases with speed indicate that stride length (disregarding the gliding phases) increases markedly with speed. Amplitude of the movements of the leading edge of the fin increases over most of the speed range, although it declines at the highest speeds observed. As in the trout, the product of finbeat frequency and amplitude increases linearly with speed in Cymatogaster, although the graph shows two discreet linear zones, seemingly reflecting two types of finbeat pattern. Abduction and adduction of the fin are equal in duration, and cyclic movements of the body suggest that thrust is derived over both phases, as described above for penguins (Webb, 1973).

In the locomotor parameters which have been characterized for all four groups, penguins more closely resemble fishes, and in particular the surf perch, more than they resemble flying birds. Birds in forward flight show at most minor variation in wingbeat frequency with speed compared to fish and penguins and are unique in applying thrust over only one half of the stroke cycle. The swimming forms all appear to derive thrust over both halves of the cycle. Fish which propel themselves with their caudal fins differ from penguins, other birds and Cymatogaster in having constant stride lengths (except at low speeds). Only penguins and Cymatogaster increase both stride length and frequency with speed, although these comparisons are complicated by the varying duration of the gliding phases and multiple finbeat patterns used by Cymatogaster.

It is difficult to explain all of the observed similarities and differences, although some hypotheses may be advanced. The similarity of the locomotory kinematics of penguins and Cymatogaster may result from similar locomotory modes. Both conform to Breder's (1926) labriform mode, in which narrow-based lateral appendages are oscillated while the body is held rigid. The nature of water flow around these animals may allow them to use or limit them to particular techniques for altering forward speed. Fishes using caudal fin 
propulsion may face a different set of constraints over or options for speed modification based on distinct qualities of water flow around their bodies.

As birds and bats fly in air they must use their wings to provide lift of an average magnitude equal to gravity. Generation of substantial amounts of thrust on the upstroke would be coupled with generation of a negative lift component, and could therefore be disadvantageous. Swimming animals, on the other hand, could utilize equivalent up- and down- (left and right) strokes in which the lift generated over a complete stroke cycle summed to zero. This pattern has obvious benefits to a neutrally buoyant animal, in which forward progression requires only thrust.

Flying birds and bats also differ from fish and penguins in having virtually constant wingbeat frequencies during forward flight. This phenomenon might be considered in terms of the model proposed by Greenewalt $(1960 \mathrm{~b})$, who likened the wings of birds and insects to driven, damped mechanical oscillators. In this model the wing, with its attendant soft tissues, is flapped at its resonant frequency with minimal energetic cost. The resonant frequency depends on the distribution of wing mass and the elasticity of the tissues tending to resist wing movement. Work against the air constitutes the external damping, and the flight muscles supply the driving force to replace lost energy. Considering the high power requirements for flight compared with other forms of animal locomotion, it seems reasonable that such a mechanism of energy conservation could be of substantial benefit to birds and bats, although at present none of their tissues has been shown to be capable of elastically storing significant quantities of energy. On the other hand, swimming animals may not be able to employ this mechanism due to the comparatively high damping capacity of water; resonance of the propulsive appendages may be prevented by the dense, viscous medium.

The frequency of oscillation of locomotory appendages is correlated with the speed of shortening of the propulsive musculature, which in turn is related to muscular power output and efficiency. As discussed by Hill (1950), the power available from and the net efficiency of muscular contraction reach maxima at shortening speeds around $30 \%$ and $20 \%$ of the maximal, unloaded contraction speed, respectively. Alexander (1973) summarizes data indicating that many animals utilize their muscles of locomotion at stress and shortening values commensurate with predictions of high power output (although he cites some unexplained departures from theoretically "ideal" shortening speeds). Goldspink (1977) summarizes correlations between the contractile, biochemical and histochemical properties of locomotory muscles and the frequencies of propulsive movements in vertebrates. Fishes attain different tailbeat frequencies without drastic losses of muscular power (or perhaps efficiency) by recruiting muscle fibre populations with higher intrinsic rates of shortening as frequency is increased. Birds, on the other hand, show apparent constancy both of flapping frequency and of intrinsic shortening speeds (typically extrapolated from histochemical data) of pectoral muscle fibres.

This seemingly close correlation between the patterns of utilization of locomotory muscles and their potential for power output over a range of shortening speeds may provide insight into two aspects of penguin swimming. First, as stated above, penguins generally modulate both wingbeat frequency and stride length with speed, while fish typically modulate the former, and birds the latter. Since forward speed is simply the product of these two parameters, penguins neither increase their frequency as much as fish nor their stride length as much as birds for a given increase in length-specific speed. 
If penguins show the homogeneity of pectoralis fibre speeds characteristic of other birds, the observation that swimming penguins show a smaller modulation of wingbeat frequency than do fish may reflect a strategy for reducing departures from those shortening speeds of the wing musculature which are optimal in terms of power output or efficiency. In this connection, it is most unfortunate that we could not determine wingbeat amplitudes because both contraction frequency of the muscles and muscular excursion must be known in order to determine whether the speed of muscular shortening changes with swimming speed.

Secondly, the gliding phases between wingbeats may also be related to muscular power and/or efficiency. They are seen in Adélie, King and Emperor penguins at all speeds, and in all species at speeds less than $1.25 \mathrm{~m} / \mathrm{sec}$. Insertion of gliding phases allows mean values for thrust (and thus speed) to be varied without altering the speed of shortening of the propulsive musculature. Cymatogaster may also employ this strategy, interposing glides between finbeats and decreasing the relative duration of these glides as speed increases (Webb, 1973).

The interjection of gliding phases by penguins may also be related to the phenomena described as "burst swimming" in fish and "intermittent flight" in birds (Weihs, 1974; Rayner, 1977). The models proposed both suggest that energetic savings result when periods of propulsion are alternated with periods of gliding. Presumably these savings are ultimately the result of a reduction in the component of drag associated with thrust generation.

It is interesting to note that the three species which typically show gliding phases include the two with the largest body size, and Adélie penguins which are among the largest of the remaining species. Because drag on a streamlined body is a function of its surface area, while momentum is a function of its mass, we would expect large gliding penguins to decelerate more slowly than small ones. Large penguins should thus be able to interpose gliding phases of a given duration with smaller resultant oscillations in their forward speed than would small penguins.

The drag coefficients of gliding Emperor penguins $\left(2 \cdot 1,3 \cdot 0\right.$ and $3 \cdot 0 \% 10^{-3}$ at Reynolds numbers of $1.25,1.62$ and $1.76 \times 10^{6}$, respectively) are approximately half the lowest values reported by Webb (1975) for fish at comparable Reynolds numbers. Considering the artifacts inherent in many techniques for measuring drag of fish, especially when dead specimens are used (Webb, 1975), the low values for drag of live, gliding penguins are not surprising. In addition, these drag coefficients are slightly less than comparable values for a smooth, flat plate with a fully turbulent boundary layer (Hoerner, 1965), suggesting that the streamlined shape of the body of penguins results in a very small pressure (form) drag, and that the boundary layer over gliding Emperor penguins is partly laminar and partly turbulent. This transitional condition is typical at the range of Reynolds numbers around $10^{6}$.

We would like to thank the Director of the Detroit Zoo, Dr James Savoy, and the Curator of Birds, Mr Keith Kline, for allowing us to work in the penguinarium before visiting hours. Conversations with the penguin keepers, Mr Edward Schierlinger and Mr Lee Ennest, were helpful and especially appreciated. The LS\&A Media Center of The University of Michigan loaned us videotape equipment and ciné lights. Carl Gans, in addition to loaning videotape and ciné-film equipment from his laboratory and functional morphology course, encouraged us from 
the inception of the work and provided many valuable comments on the manuscript. For most of the period of the project, W.B. was supported by an NSF Predoctoral Fellowship. Supported by NSF DEB 77-02605 to Carl Gans.

\section{REFERENCES}

Alexander, R. McN. (1973). Muscle performance in locomotion and other strenuous activities. In Comparative physiology: 1-21. Bolis, L., Schmidt-Nielsen, K. \& Maddrell, S. H. P. (Eds). Amsterdam: North Holland.

Aulie, A. (1970). Electrical activity from the pectoral muscle of a flying bird, the budgerigar. Comp. Biochem. Physiol. 36: 297-300.

Aulie, A. (1971). Co-ordination between the activity of the heart and the flight muscles during flight in small birds. Comp. Biochem. Physiol. 38A: 91-97.

Aulie, A. (1972). Co-ordination between the activity of the heart and the pectoral muscles during flight in the pigeon. Comp. Biochem. Physiol. 41A: 43-48.

Bainbridge, R. (1958). The speed of swimming of fish as related to size and to the frequency and amplitude of the tail beat. J. exp. Biol. 35: 109-133.

Bernstein, M. H., Thomas, S. P. \& Schmidt-Nielsen, K. (1973). Power input during flight of the fish crow, Corvus ossifragus. J. exp. Biol. $58: 401-410$.

Breder, C. M. (1926). The locomotion of fishes. Zoologica, N.Y. 4: 159297.

Brooks, A. (1945). The underwater actions of diving ducks. Auk 62: 517-523.

Brown, R. H. J. (1948). The flight of birds: the flapping cycle of the pigeon. J. exp. Biol. 25: 322-333.

Brown, R. H. J. (1963). The flight of birds. Biol. Rev. 38: 460-489.

Dabelow, A. (1925). Die Schwimmanpassung der Vögel. Ein Beitrag zur biologischen Anatomie der Fortbewegung. Morph. Jb. 54: 288-321.

Drake, J. (1969). Penguinarium at Detroit Zoo. Int. Zoo Yb. 9: 69-70.

Frank, H. R. \& Neu, W. (1929). Die Schwimmbewegungen der Tauchvögel (Podiceps). Z. vergl. Physiol. 10: $410-418$.

Gervais, P. \& Alix, E. (1877). Osteologie et myologie des manchots ou spheniscides. J. Zool., Paris 6: 424-472.

Goldspink, G. (1977). Muscle energetics and animal locomotion. In Mechanics and energetics of animal locomotion: 57-114. Alexander, R. McN. \& Goldspink, G. (Eds). New York: John Wiley and Sons.

Greenewalt, C. H. (1960a). Hummingbirds. New York: Doubleday and Co.

Greenewalt, C. H. (1960b). The wings of insects and birds as mechanical oscillators. Proc, Am. phil. Soc. 104: 605-611.

Greenewalt, C. H. (1975). The flight of birds. Trans. Am. phil. Soc. (N. S.) 65(4): 1-67.

Hagiwara, S., Chichibu, S. \& Simpson, N. (1968). Neuromuscular mechanisms of wingbeat in hummingbirds Z. vergl. Physiol. 60: 209-218.

Hill, A. V. (1950). The dimensions of animals and their muscular dynamics. Sci. Progr. 38: 209-230.

Hoerner, S. F. (1965). Fluid dynamic drag. Brick Town, New Jersey: published by the author.

Hudson, R. C. L. (1973). On the function of the red and white muscles in teleosts at intermediate swimming speeds. J. exp. Biol. 58: 509-522.

Hunter, J. R. \& Zweifel, J. R. (1971). Swimming speed, tail beat frequency, tail beat amplitude, and size in jack mackerel, Trachurus symmetricus and other fishes. Fishery Bull, U.S. 69: 253-266.

Kooyman, G. L., Drabek, C. M., Elsner, R. \& Campbell, W. B. (1971). Diving behavior of the Emperor penguin, Aptenodytes forsteri. Auk 88: 775-795.

Le Maho, Y. (1977). The emperor penguin: A strategy to live and breed in the cold. Am. Scient. 65: 680-693.

McGahan, J. (1973). Flapping flight of the Andean condor in nature. J. exp. Biol. 58: 239-253.

Meister, W. (1962). Histological structure of the long bones of penguins. Anat. Rec. 143: 377-388.

Neu, W. (1931). Schwimmbewegungen der Tauchvögel. Z. vergl. Physiol. 14: 682-708.

Norberg, U. M. (1976). Aerodynamics, kinematics and energetics of horizontal flapping flight in the long eared bat Plecotus auritus. J. exp. Biol. 65: 179-212.

Owen, R. (1866). Comparative anatomy and physiology of vertebrates. 2: London: Longmans, Green and Co.

Owre, O. T. (1967). Adaptations for locomotion in the anhinga and the double crested cormorant. Orn. Monogr. 6: 5-138.

Pennycuick, C. (1968). Power requirements for horizontal flight in the pigeon Columba livia. J. exp. Biol. 49: 527-555. 
Rayner, J. (1977). The intermittent flight of birds. In Scale effects in animal locomotion: 437-444. Pedley, T. J. (Ed.). London: Academic Press.

Romer, A. S. (1959). The vertebrate story. 4th ed. Chicago: Univ. of Chicago Press.

Schnitzler, H. U. (1971). Fledermäuse im Windkanal. Z. vergl. Physiol. 73: 209-221.

Shufeldt, R. W. (1901). Osteology of the penguins. J. Anat. Physiol., Lond. 35: 390 404.

Simpson, G. G. (1946). Fossil penguins. Bull. Am. Mus, nat. Hist. 87: 1-99.

Simpson, G. G. (1976). Penguins: past and present, here and there. New Haven: Yale Univ. Press.

Spring, L. (1971). A comparison of functional and morphological adaptations in the common murre (Uria aalge) and thick billed murre (Uria lomvia). Auk 73: 1-27.

Stegman, B. K. (1970). [Peculiarities of morphology of the wing in penguins.] Trudy zool. Inst. Leningr. 47:236-248. [In Russian].

Stettenheim, P. (1959). Adaptations for underwater swimming in the common murre (Uria aalge). Ann Arbor: Doctoral Thesis, Univ, of Michigan.

Stonehouse, B. (1967). The general biology and thermal balance of penguins. In Advances in ecological research 4 : 131-196. Cragg, J. B. (Ed.). London: Academic Press.

Storer, R. W. (1958). Evolution in the diving birds. Int. Orn. Congr. 12: 694-707.

Terres, J. K. (1968). How birds fly. New York: Hawthorn Books.

Thomas, S. P. \& Suthers, R. A. (1973). The physiology and energetics of bat flight. J. exp. Biol. 57: $317-335$.

Tucker, V. A. (1966). Oxygen consumption of a flying bird. Science, N.Y. 154: 150-151.

Tucker, V. A. (1972). Metabolism during flight in the laughing gull, Larus atricilla. Am. J. Physiol. 222: $237-245$.

Wardle, C. S. (1975). Limit of fish swimming speed. Nature, Lond. 255: 725-727.

Webb, P. W. (1971). The swimming energetics of trout. I. Thrust and power output at cruising speeds. J. exp. Biol. 55: $489-520$.

Webb, P. W. (1973). Kinematics of pectoral fin propulsion in Cymatogaster aggregata. J. exp. Biol. 59: 697-710.

Webb, P. W. (1975). Hydrodynamics and energetics of fish propulsion. Bull. Fish. Res. Bd Can. No. 190.

Weihs, D. (1974). Energetic advantages of burst swimming of fish. J. theor. Biol. 48: 215-229. 